\title{
Carboxyl-Terminal Residues N478 and V479 Required for the Cytolytic Activity of Listeriolysin O Play a Critical Role in Listeria monocytogenes Pathogenicity
}

OPEN ACCESS

Edited by:

Hao Shen,

University of Pennsylvania,

United States

Reviewed by:

Laurel L. Lenz,

University of Colorado

Denver School of Medicine,

United States

Rebecca Leigh Schmidt,

Upper lowa University,

United States

*Correspondence:

Houhui Song

songhh@zafu.edu.cn

tThese authors have contributed equally to the work.

Specialty section:

This article was submitted to Microbial Immunology, a section of the journal

Frontiers in Immunology

Received: 28 August 2017 Accepted: 17 October 2017 Published: 01 November 2017

Citation:

Cheng $C$, Jiang L, Ma T, Wang $H$, Han X, Sun J, Yang Y, Chen Z, Yu H, Hang Y, Liu F, Wang B, Fang W, Huang $H$, Fang $C$, Cai $C$, Freitag $N$

and Song H (2017) Carboxyl-

Terminal Residues N478 and V479

Required for the Cytolytic Activity of Listeriolysin O Play a Critical

Role in Listeria monocytogenes

Pathogenicity.

Front. Immunol. 8:1439.

doi: 10.3389/fimmu.2017.01439

\section{Changyong Cheng't, Li Jiang ${ }^{1 \dagger}$, Tiantian Ma', Hang Wang', Xiao Han', Jing Sun', Yongchun Yang', Zhongwei Chen', Huifei Yu', Yi Hang', Fengdan Liu', Bosen Wang', Weihuan Fang ${ }^{1,2}$, Huarong Huang ${ }^{3}$, Chun Fang ${ }^{4}$, Chang Cai ${ }^{1,5}$, Nancy Freitag ${ }^{6}$ and Houhui Song ${ }^{\text {** }}$}

\begin{abstract}
College of Animal Science and Technology of Zhejiang A\&F University, China-Australian Joint Laboratory for Animal Health Big Data Analytics, Zhejiang Provincial Engineering Laboratory for Animal Health Inspection \& Internet Technology, Lin'an, China, ${ }^{2}$ Zhejiang University Institute of Preventive Veterinary Medicine, Zhejiang Provincial Key Laboratory of Preventive Veterinary Medicine, Hangzhou, China, ${ }^{3}$ College of Biological and Environmental Science, Institute of Developmental and Regenerative Biology, Hangzhou Normal University, Hangzhou, China, ${ }^{4}$ College of Animal Science, Yangtze University, Hubei, China, ${ }^{5}$ School of Veterinary and Life Sciences, Murdoch University, Murdoch, WA, Australia, ${ }^{6}$ Department of Microbiology and Immunology, University of Illinois at Chicago College of Medicine, Chicago, IL, United States
\end{abstract}

Listeria monocytogenes is a facultative intracellular pathogen that secretes the cytolysin listeriolysin O (LLO), which enables the bacteria to cross the phagosomal membrane. $L$. monocytogenes regulates LLO activity in the phagosome and minimizes its activity in the host cytosol. Mutants that fail to compartmentalize LLO activity are cytotoxic and have attenuated virulence. Here, we showed that residues N478 and V479 of LLO are required for LLO hemolytic activity and bacterial virulence. A single N478A mutation (LLON478A) significantly increased the hemolytic activity of LLO at a neutral $\mathrm{pH}$, while no difference was observed at the optimum acidic $\mathrm{pH}$, compared with wild-type LLO. Conversely, the mutant LLOV479A exhibited lower hemolytic activity at the acidic pH, but not at the neutral $\mathrm{pH}$. The double mutant LLO $\mathrm{N} 478 A v 479 A_{\text {s }}$ showed a greater decrease in hemolytic activity at both the acidic and neutral pHs. Interestingly, strains producing LLO $_{\text {N478A }}$ or LLO ${ }_{V 479 A}$ lysed erythrocytes similarly to the wild-type strain. Surprisingly, bacteria-secreting LLON478Av479A had barely detectable hemolytic activity, but exhibited host cell cytotoxicity, escaped from the phagosome, grew intracellularly, and spread cell-to-cell with the same efficiency as the wild-type strain, but were highly attenuated in virulence in mice. These data demonstrate that these two residues are required for LLO hemolytic activity and pathogenicity in mice, but not for escape from the phagosome and cell-to-cell spreading. The finding that the nearly non-hemolytic LLON478Av479A mutant grew intracellularly indicates that mutagenesis of a virulence determinant is a novel approach for the development of live vaccine strains.

Keywords: Listeria monocytogenes, listeriolysin O, cytolytic activity, virulence, live vaccine 


\section{INTRODUCTION}

The Gram-positive, facultative intracellular bacterium Listeria monocytogenes is the causative agent of listeriosis, a severe foodborne infection with a high mortality rate (1). This pathogen is ubiquitous, and it has been isolated from humans and animals, as well as from raw and ready-to-eat foods $(2,3)$, and it is capable of invading a wide variety of eukaryotic cells, including endothelial cells and macrophages $(4,5)$. Each step of a successful infection established by $L$. monocytogenes is highly dependent upon the production of virulence-associated factors $(1,6,7)$. Among these virulence factors, listeriolysin O (LLO, encoded by the hly gene) plays a central role in the escape of bacteria from the phagosomal compartment, and it is also involved in cell-to cell spreading (8), thus making LLO an essential determinant of $L$. monocytogenes pathogenesis. LLO belongs to the family of cholesterol-dependent cytolysins (CDCs) that are secreted by many pathogenic Gram-positive bacteria (9), and CDCs are the largest family among the bacterial pore-forming toxins $(10,11)$. Other members include more than 20 pore-forming toxins produced by different bacterial species, like anthrolysin $\mathrm{O}$, streptolysin $\mathrm{O}$, perfringolysin $\mathrm{O}$ (PFO), and pneumolysin. All CDCs are secreted as soluble monomers by their cognate bacteria and are characterized by their ability to bind to the cholesterol of host membranes and form large pores (8).

The most heterogeneous and better studied region of CDCs is the amino $(\mathrm{N})$-terminal sequence, which harbors distinct functions for some of the family members (11). L. monocytogenes LLO is composed of 529 residues and possesses at its $\mathrm{N}$-terminus a 25-residue-long typical signal peptide. To maintain its intracellular niche, L. monocytogenes must restrict the pore-forming activity of LLO to the phagosomal compartment and prevent perforation of the plasma membrane. Correct compartmentalization of LLO activity requires a 26 -amino-acid sequence located in the extreme $\mathrm{N}$-terminus of the protein, which resembles a eukaryotic PEST-like sequence that is rich in the amino acids proline, glutamate, serine, and threonine $(12,13)$. Mutants lacking the PEST-like region exhibit higher intracellular LLO levels and increased cytotoxicity, and, therefore, result in a higher permeability of the host plasma membrane, which consequently decreases the virulence of the bacteria because they are no longer able to evade host extracellular defenses (4, 13, 14). Recently, Koster and colleagues determined the crystal structure of natively produced $L$. monocytogenes LLO, which showed that the N-terminal PEST-like sequence forms a lefthanded polyproline type II helix that is involved in intra- and intermolecular interactions (11). Among the pore-forming toxin family members, LLO is the only cytolysin that is made by an intracellular pathogen, and it has a pronounced acidic $\mathrm{pH}$ optimum (pH 5.5) (15), which is attributed to the sophisticated regulation of its activity via a $\mathrm{pH}$ sensor consisting of the three acidic residues E247, D208, and D320 (the "acidic triad") (16). However, $\mathrm{PFO}$ does not have a pronounced acidic $\mathrm{pH}$ optimum, but rather is active at both acidic and neutral pHs. Moreover, the high cytotoxicity of secreted PFO that strongly permeabilizes the host cell is caused in part by the lack of a PEST-like sequence, which targets LLO for phosphorylation and degradation in the cytosol (12). As a result, L. monocytogenes expressing PFO in place of LLO is capable of escaping from a host vacuole in vitro, but is unable to grow intracellularly and is non-virulent (17). Thus, LLO is unique, not in its ability to mediate vacuolar escape, but in its lack of host-cell toxicity. Interestingly, the level of LLO hemolytic activity does not correlate with the efficiency of Listeria escape from the vacuole within host cells. A previous study employed an intracellular genetic selection to isolate mutants in PFO that supported the intracellular growth of L. monocytogenes, and it identified several PFO mutants containing a single amino acid change that had low or undetectable hemolytic activity. Nevertheless, these non-hemolytic mutants were still capable of escaping from the phagocytic vacuole of J774 macrophages, albeit less efficiently than the wild-type strain (18).

In comparison to the thoroughly studied $\mathrm{N}$-terminus of CDCs, little is known about the carboxyl (C)-terminus of this protein family. So far as we know, all CDCs contain a highly conserved undecapeptide (ECTGLAWEWWR) at their C-terminus, which was originally thought to be critical for cholesterol-mediated membrane recognition, as mutations in it abolished pore formation (19). However, the mechanistic contribution of this domain is unclear. Recently, it was demonstrated that the undecapeptide was not responsible for cholesterol binding. Instead, a threonineleucine pair in the C-terminal part of the protein was important (20). In fact, the conserved undecapeptide was shown to be a key structural element that allows the correct conformation of the cholesterol-binding motif (21). In the present study, we used site-directed mutagenesis to identify a double-residue mutant $\left(\mathrm{LLO}_{\mathrm{N} 47 \mathrm{AAV} 479 \mathrm{~A}}\right)$ close to the undecapeptide region of LLO that rendered LLO almost inactive, yet, still mediated vacuolar escape, intracellular growth, and cell-to-cell spreading with an efficiency close to that of the wild-type strain, even though it was completely non-virulent in mice. These results demonstrate that these two residues are active sites that are required for LLO hemolytic activity and, therefore, are essential for Listeria infections of mice. Here, we addressed the role of this region in the biological activities of LLO and concluded that the virulence, but not the intracellular fate, of $L$. monocytogenes directly correlated with LLO hemolytic activity. Furthermore, the attenuated virulence of the $\mathrm{LLO}_{\mathrm{N} 478 \mathrm{AV} 479 \mathrm{~A}}$ mutant suggests that it has great potential as a live vaccine vehicle.

\section{RESULTS}

\section{Residues N478 and V479 within LLO Are Required for Hemolytic Activity}

We previously generated an L. monocytogenes mutant strain for intracellular antigen-presenting containing a 12 -amino-acid inframe deletion (472-GNARNINVYAKE-483) at the C-terminus of LLO that could form an LPXTG motif (Figure 1A), a characteristic C-terminal sorting signal known to direct covalent anchoring to the peptidoglycan of Gram-positive bacteria. Surprisingly, its ability to lyse erythrocytes was completely impaired, suggesting that the deleted 12 residues might be required for LLO cytolytic activity, which prompted us to further investigate which single 

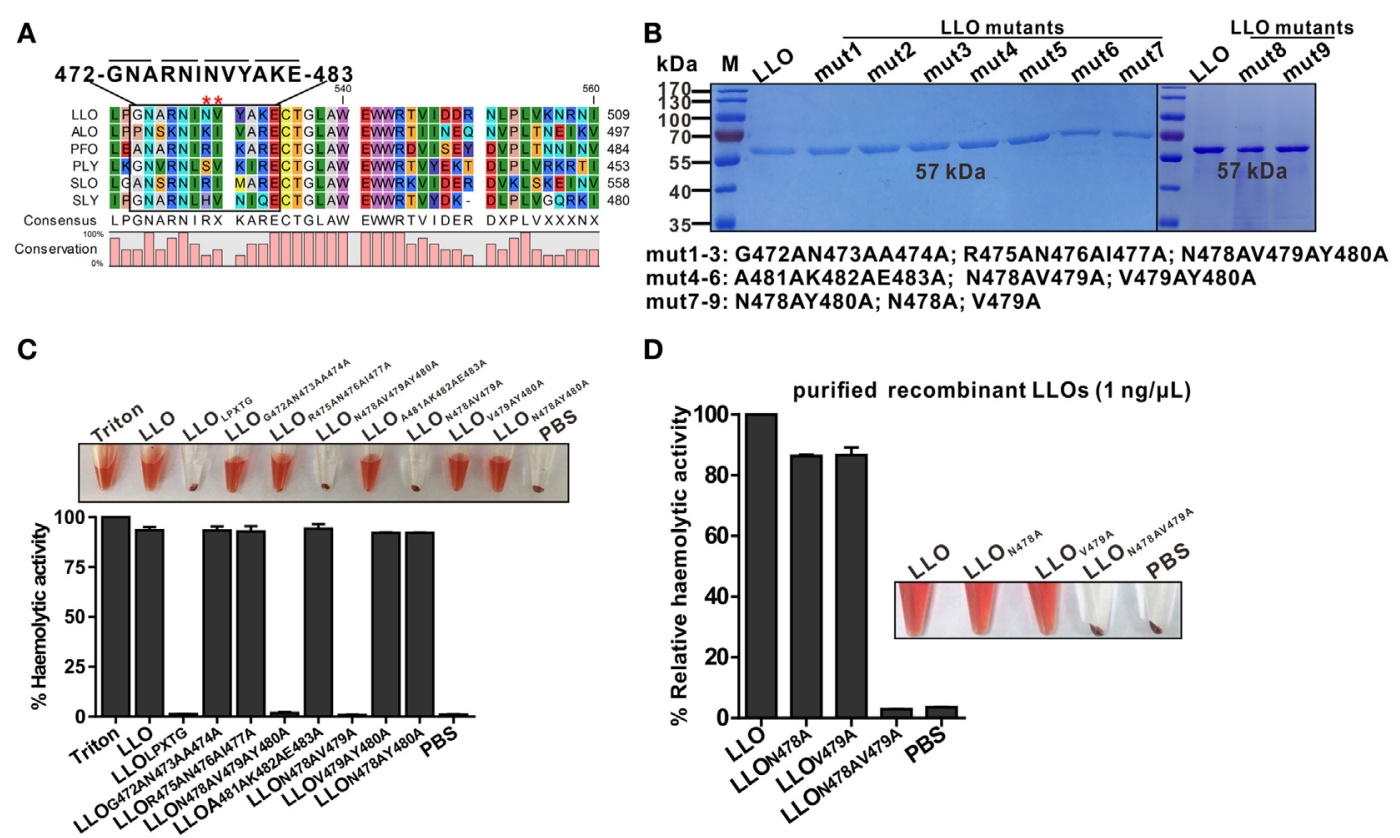

D
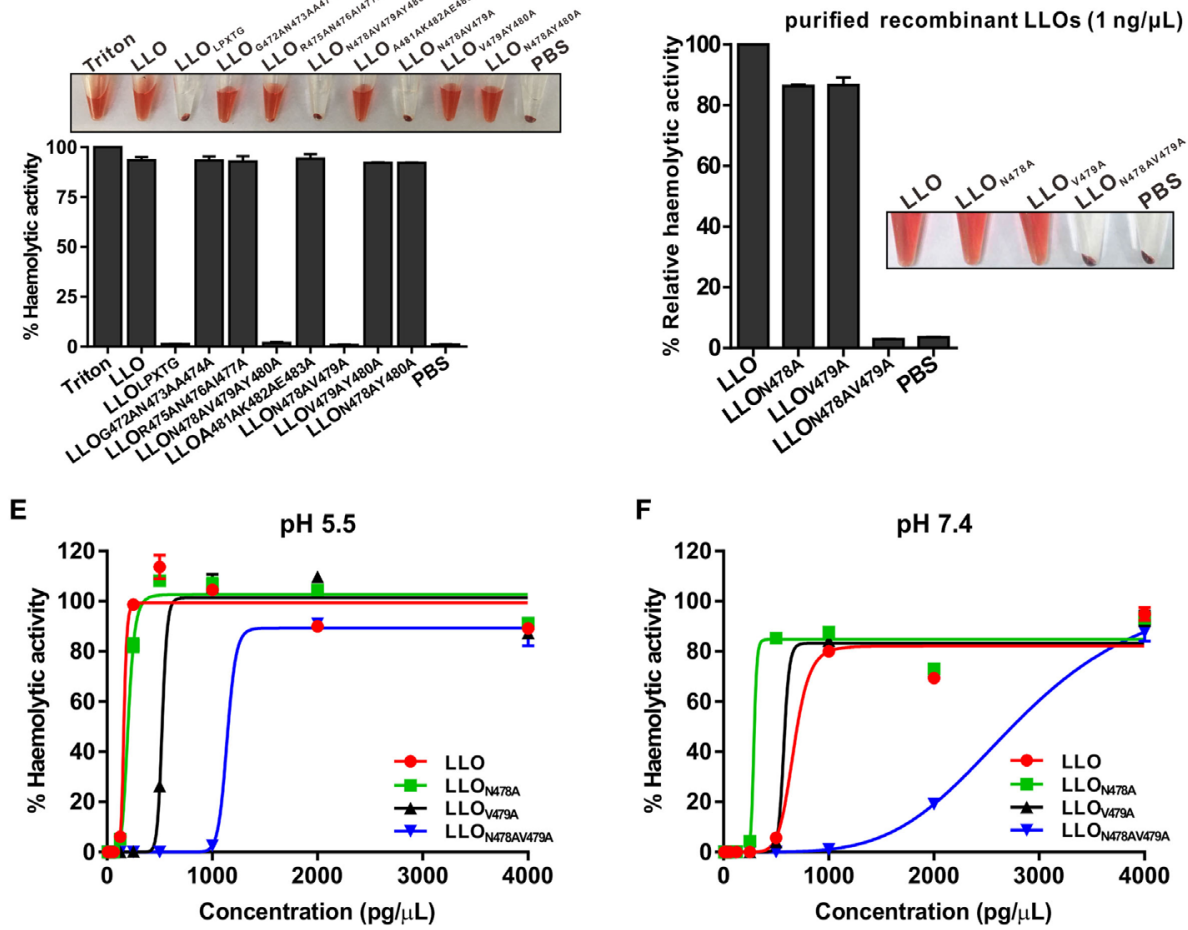

FIGURE 1 | Residues N478 and V479 of listeriolysin O (LLO) are required for hemolytic activity. (A) The strategy for the generation of a mutated LLO with a 12-amino-acid in-frame deletion (472-GNARNINVYAKE-483) that could form an LPXTG motif. Stars indicate the identified key residues, N478 and V479, of LLO. The listed toxins are from the following organisms: LLO, L. monocytogenes listeriolysin; ALO, Bacillus anthracis anthrolysin; PFO, Clostridium perfringens perfringolysin; PLY, Streptococcus pneumoniae pneumolysin; SLO, Streptococcus pyogenes streptolysin; SLY, Streptococcus suis suilysin. (B) Sodium dodecyl sulfate-polyacrylamide gel electrophoresis analysis of the purified histidine-tagged recombinant LLO and its mutated forms expressed in Escherichia coli. (C,D) Comparison of the hemolytic activity of the LLO mutants relative to wild-type LLO. Erythrocytes incubated with $1 \%$ Triton X-100 or phosphate-buffered saline (PBS) served to determine the maximum (100\%) and minimum (0\%) hemolytic activity, respectively. (E,F) Hemolytic activity of the identified LLO mutants, LLON478A, $L_{\text {LLO }} 479 A$, and LLON478Av479A, at various concentrations $(0-4 \mathrm{ng} / \mathrm{ML})$ at $\mathrm{pH} 5.5$ (E) and 7.4 (F). Erythrocytes incubated with $1 \%$ Triton X-100 or PBS served to determine the maximum (100\%) and minimum (0\%) hemolytic activity, respectively. Data in C, D, E, and F are expressed as means \pm SDs of three independent experiments.

amino acid among these 12 residues plays a decisive role in modulating the LLO activity. Using site-directed mutagenesis, we generated a series of different combinations of double and triple mutant LLO proteins, which were then expressed as C-terminally histidine-tagged recombinant proteins in Escherichia coli and purified to homogeneity by nickel-affinity chromatography to analyze their hemolytic activity (Figure 1B). As expected, we found that among all the LLO mutants, only the mutant proteins $\mathrm{LLO}_{\mathrm{N} 478 \mathrm{AV} 479 \mathrm{AY} 480 \mathrm{~A}}$ and $\mathrm{LLO}_{\mathrm{N} 478 \mathrm{AV} 479 \mathrm{~A}}$ completely lost their hemolytic activity, while the others lysed erythrocytes as efficiently as wild-type LLO (Figure 1C), suggesting that residues N478 and V479 are critical for LLO activity. Based on this observation, we generated two single-amino-acid mutants $\left(\mathrm{LLO}_{\mathrm{N} 478 \mathrm{~A}}\right.$ and
$\mathrm{LLO}_{\mathrm{V} 479 \mathrm{~A}}$ ) to determine, which residue was essential for controlling the cytolytic activity of LLO. Strikingly, the mutation of either N478A or V479A had little effect on the hemolytic activity of LLO at a concentration of $1 \mathrm{ng} / \mu \mathrm{L}$, which was sufficient for wild-type LLO to completely perforate erythrocyte membranes and led to full hemolytic activity (Figure 1D). Previous studies established that pore formation by LLO is $\mathrm{pH}$ sensitive and concentration dependent at the host temperature $\left(37^{\circ} \mathrm{C}\right)$, with LLO being more active at an acidic $\mathrm{pH}$ (16). Therefore, the N478A, V479A, and N478AV479A mutants at various concentrations were further tested for hemolysis at $\mathrm{pH} 5.5$ and 7.4. As shown, the $\mathrm{LLO}_{\mathrm{N} 478 \mathrm{~A}}$ mutant had slightly higher LLO hemolytic activity at a neutral $\mathrm{pH}$, while no difference in activity was observed 
at the acidic $\mathrm{pH}$ optimum of this cytolysin, compared with wild-type LLO (Figures 1E,F). Conversely, the mutant $\mathrm{LLO}_{\mathrm{V} 479 \mathrm{~A}}$ exhibited lower hemolytic activity at the acidic $\mathrm{pH}$, but not at the neutral $\mathrm{pH}$. In addition, the $\mathrm{LLO}_{\mathrm{N} 478 \mathrm{AV} 479 \mathrm{~A}}$ mutant showed a $100 \%$ decrease in hemolytic activity compared with wild-type LLO at both the acidic and neutral $\mathrm{pHs}$ at a low concentration (less than or equal to $1 \mathrm{ng} / \mu \mathrm{L}$ ) (Figures 1E,F). However, to our surprise, the native hemolytic activity of $\mathrm{LLO}_{\mathrm{N} 478 \mathrm{AV} 479 \mathrm{~A}}$ was fully restored by increasing its concentration to 2 and $4 \mathrm{ng} / \mu \mathrm{L}$ at $\mathrm{pH}$ 5.5 and 7.4, respectively (Figures 1E,F). LLO $_{\mathrm{N} 478 \mathrm{AV} 479 \mathrm{~A}}$ can be considered as a non-hemolytic LLO mutant mainly for two reasons. One is the fact that wild-type LLO exhibits very efficient hemolytic activity in vitro and results in complete erythrocyte lysis at $\mathrm{pH} 5.5$ at a very low concentration of approximately $0.1 \mathrm{ng} / \mu \mathrm{L}(\sim 0.25 \mathrm{ng} / \mu \mathrm{L}$ in our study) (11). Another reason is that a similar mutation $\left(\mathrm{LLO}_{\mathrm{E} 262 \mathrm{~K}}\right)$ rendered LLO virtually inactive at low concentrations, but relatively active at a higher concentration of $1 \mathrm{ng} / \mu \mathrm{L}$ (11). Moreover, LLO and its active mutants have a pronounced acidic $\mathrm{pH}$ optimum and remain relatively inactive at neutral $\mathrm{pH}$. Collectively, these results showed clearly that residues N478 and V479 are required for LLO hemolytic activity.

\section{L. monocytogenes Expressing LLO N478AV479A Lacks Hemolytic Activity but Is Cytotoxic to Host Cell Membranes}

Having established that the $\mathrm{LLO}_{\mathrm{N} 478 \mathrm{AV} 479 \mathrm{~A}}$ mutation significantly impaired the activity of purified LLO, we further complemented the $\Delta h l y$ mutant strain with wild-type LLO, LLO ${ }_{\mathrm{N} 478 \mathrm{~A}}$, $\mathrm{LLO}_{\mathrm{V} 479 \mathrm{~A}}$, or $\mathrm{LLO}_{\mathrm{N} 478 \mathrm{AV} 479 \mathrm{~A}}$ under the natural hly promoter using the Listeria integrative plasmid, pIMK2. As shown by western blotting (Figure 2A), the four resulting mutant strains, $\mathrm{C} \Delta h l y$,

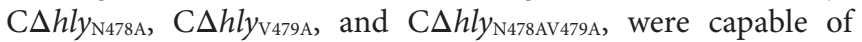
expressing and secreting LLO or its mutant forms in comparable amounts to wild-type LLO in the culture supernatant, suggesting that these amino acid substitutions did not affect LLO synthesis and secretion. Moreover, we found that these mutations also had no effect on bacterial growth in vitro (Figure 2A). Furthermore, the hemolytic activities recorded in the supernatants of the mutants $\mathrm{C} \Delta h l y, \mathrm{C} \Delta h l_{\mathrm{N} 478 \mathrm{~A}}$, and $\mathrm{C} \Delta h l_{\mathrm{V} 479 \mathrm{~A}}$ were comparable to that of the wild-type EGD-e strain, whereas the C $\Delta h l_{\mathrm{N} 478 \mathrm{AV} 479 \mathrm{~A}}$ mutant did not exhibit any detectable hemolytic activity, similar to the $\Delta$ hly mutant (Figure 2B). Consistent with the hemolytic data obtained from the recombinant LLO variants, we conclude that $L$. monocytogenes expressing $\mathrm{LLO}_{\mathrm{N} 478 \mathrm{Av} 479 \mathrm{~A}}$ is
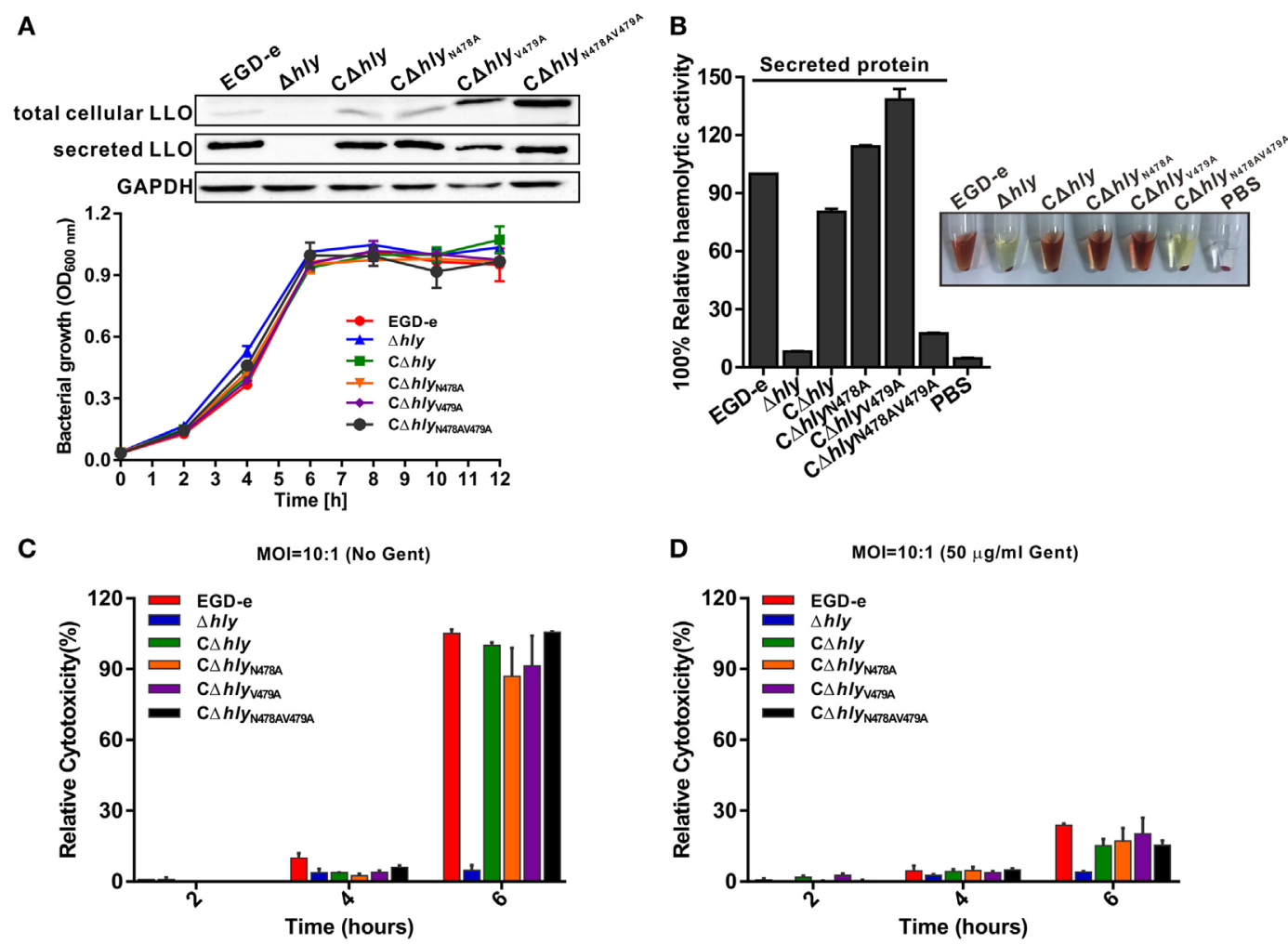

FIGURE 2 | Listeria monocytogenes expressing LLO ${ }_{\text {N478Av479A }}$ lacks hemolytic activity but is cytotoxic to host cell membranes. (A) Secreted listeriolysin O (LLO) was detected by western blotting, and in vitro bacterial growth of the L. monocytogenes wild-type EGD-e and $\Delta$ hly strains, and the complemented strains C $\Delta h l y$,

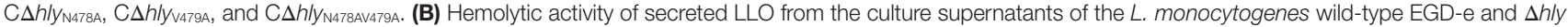

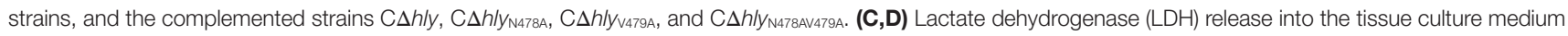
was used to monitor the perforation of the host cell plasma membrane. The percentage of the maximal LDH release from monolayers of J774 macrophages infected with the indicated $L$. monocytogenes strains at 2,4 , and $6 \mathrm{~h}$ postinfection in the presence or absence of gentamicin $(50 \mu \mathrm{g} / \mathrm{mL})$ is indicated. All the data are expressed as means \pm SDs of three independent experiments. 
indeed non-hemolytic. To monitor directly the cytotoxicity of the different LLO constructs, we detected the release of a host cytosolic enzyme, lactate dehydrogenase (LDH), into the tissue culture medium from infected J774 macrophages. At early timepoints during the infection ( 2 and $4 \mathrm{~h}$ ) with any of these strains, very little detectable $\mathrm{LDH}$ was released either in the presence or absence of gentamicin (Figures 2C,D). After $6 \mathrm{~h}$ of infection, the amount of released LDH from all the infected cells, except for the avirulent $\Delta h l y$ strain, increased significantly, especially in the absence of gentamicin (Figure 2C). However, to our surprise, the amount of $\mathrm{LDH}$ released from macrophages infected with the non-hemolytic $\mathrm{C} \Delta h l_{\mathrm{N} 478 \mathrm{AV} 479 \mathrm{~A}}$ strain after $6 \mathrm{~h}$ of infection was comparable to those of the hemolytic strains, including the wild-type EGD-e, C $\Delta h l y, \mathrm{C} \Delta h l y_{\mathrm{N} 478 \mathrm{~A}}$, and $\mathrm{C} \Delta h l_{\mathrm{V} 479 \mathrm{~A}}$ strains (Figure 2C), indicating that L. monocytogenes expressing $\mathrm{LLO}_{\mathrm{N} 478 \mathrm{AV} 479 \mathrm{~A}}$ lacks hemolytic activity but exhibits normal cytotoxicity to host cell membranes. As expected, when J774 cells were incubated in the constant presence of $50 \mu \mathrm{g} / \mathrm{mL}$ gentamicin, much less LDH was released during a 6-h infection by any strain compared with those in the absence of gentamicin, which was presumably due to the fact that permeabilization of the cells allowed the influx of gentamicin, which then killed the intracellular bacteria (Figure 2D) and prevented further permeabilization and $\mathrm{LDH}$ release.

\section{The N478V479 Mutation of LLO Reduces Virulence in Mice}

The virulence of the mutant strains was evaluated in a murine listeriosis model. ICR mice were inoculated intraperitoneally with $\sim 10^{6}$ bacteria, and their survival was monitored for up to 7 days after infection. To our surprise, all the mice infected with the bacteria synthesizing $\operatorname{LLO}_{\mathrm{N} 478 \mathrm{AV} 479 \mathrm{~A}}$ survived, similar to those infected with the avirulent $\Delta h l y$ strain (Figure 3A). In contrast, infection with the same number of the complemented strain synthesizing wild-type LLO led to $60 \%$ mortality $(P<0.001)$, which was comparable to that of the parental strain that exhibited $70 \%$ mortality (Figure 3A). Interestingly, the other two complemented strains expressing $\mathrm{LLO}_{\mathrm{N} 478 \mathrm{~A}}$ and $\mathrm{LLO}_{\mathrm{V} 479 \mathrm{~A}}$ resulted in 40 and $60 \%$ mortality, respectively, albeit with a relatively low lethal efficiency (Figure 3A). Moreover, the number of colony-forming units (CFU) recovered from the spleens and livers of infected mice after 24 and $48 \mathrm{~h}$ of infection was significantly lower $(\sim 2-3$ orders of magnitude) for the $\mathrm{C} \Delta h l_{\mathrm{N} 478 \mathrm{AV} 479 \mathrm{~A}}$ mutant compared
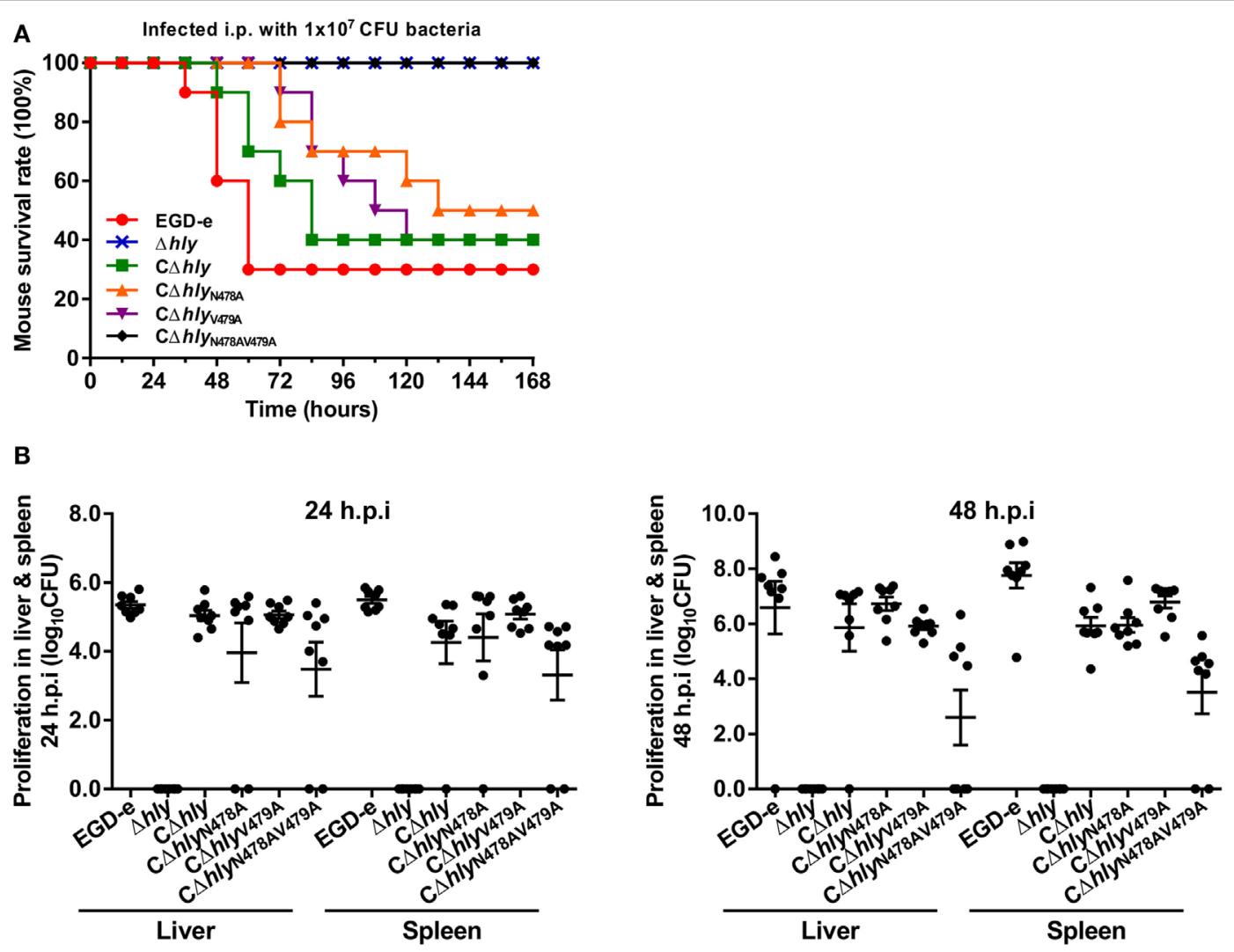

FIGURE 3 | The N478V479 mutation of listeriolysin O reduces virulence in mice. (A) The Kaplan-Meier curve represents the survival of ICR mice over time. Ten mice in each experimental group were infected intraperitoneally with $1 \times 10^{7} \mathrm{CFU}$ of Listeria monocytogenes and monitored for up to 7 days after infection. Data are represented as the percentage survival over time, and significance was determined via a log-rank test. (B) The $L$. monocytogenes wild-type EGD-e $\Delta$ hly strains, and

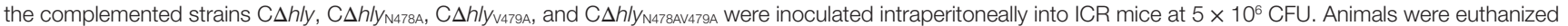
24 and $48 \mathrm{~h}$ after infection and organs (liver and spleen) were recovered and homogenized, and the homogenates were serially diluted and plated on brain-heart infusion (BHI) agar. The numbers of bacteria colonizing the liver and spleen are expressed as means \pm SDs of the log ${ }_{10} \mathrm{CFU}$ per organ for each group. 
with the strain expressing wild-type LLO (Figure 3B), indicating that the $\mathrm{C} \Delta h l_{\mathrm{N} 478 \mathrm{AV} 479 \mathrm{~A}}$ mutant was severely attenuated for virulence, and that mice infected with this mutant exhibited significantly lower bacterial burdens compared with the mice infected with the wild-type strain. As expected, no detectable bacteria were recovered from the organs of mice infected with the avirulent $\Delta h l y$ strain, and the virulence of this mutant was fully restored by complementing it with wild-type $L L O, L_{L} O_{N 478 A}$, or $\mathrm{LLO}_{\mathrm{V} 479 \mathrm{~A}}$. Taken together, these results establish a critical role for these two residues of LLO in the virulence of $L$. monocytogenes.

\section{The LLO N478V479 Mutation Does Not Affect the Efficiency of Intracellular Growth in Macrophages}

We investigated the ability of wild-type L. monocytogenes and the LLO mutants to grow intracellularly in murine-derived macrophages J774 and RAW264.7 cells. In this assay, adding the antibiotic gentamicin to the culture medium kills extracellular bacteria, but has no measurable effect on the growth of intracellular bacteria. During the infection process, intracellular proliferation of the LLO-deleted avirulent $\Delta$ hly strain was almost completely impaired compared with the wild-type strain (Figure 4A). Such compromised bacterial cell proliferation of the $\Delta h l y$ strain was finely restored in the complemented strains $\mathrm{C} \Delta h l y, \mathrm{C} \Delta h l y_{\mathrm{N} 478 \mathrm{~A}}$, or $\mathrm{C} \Delta h l y_{\mathrm{V} 479 \mathrm{~A}}$, which secrete the same amount of active LLO as the wild-type EGD-e strain (Figure 4A). Unexpectedly, the $\Delta h l y$ bacteria complemented with an inactive LLO (C $\left.\Delta h l_{\mathrm{N} 478 \mathrm{AV} 479 \mathrm{~A}}\right)$ also grew well within J774 macrophages, with an efficiency that was nearly identical to

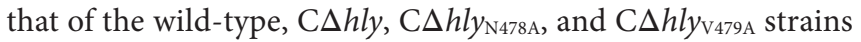
(Figure 4A). To further confirm these data, we conducted this experiment in another murine-derived macrophage cell line, RAW264.7, and the results were completely consistent with those obtained in J774 macrophages (Figure 4B). Therefore, the fact that the mutant strain $\mathrm{C} \Delta h \mathrm{y}_{\mathrm{N} 478 \mathrm{AV} 479 \mathrm{~A}}$, which had barely detectable hemolytic activity, grew intracellularly with the same efficiency as strains with wild-type levels of activity suggests that the LLO N478V479 mutation does not affect the efficiency of intracellular growth in macrophages, and, more interestingly, that the level of hemolytic activity does not correlate with the efficiency of proliferation within macrophages.

\section{L. monocytogenes Expressing LLO $\mathrm{N}_{\mathrm{N} 47 \mathrm{~V} 479}$ Is Not Defective in Cell-to-Cell Spreading}

Listeriolysin O plays an essential role in the escape of L. monocytogenes from both the primary phagosome and the secondary double-membrane-bound vesicle formed during cell-to-cell spreading (22). The data above did not directly address whether the $\mathrm{LLO}_{\mathrm{N} 487 \mathrm{~V} 479}$ mutation affects bacterial cell-to-cell spreading. Therefore, we examined the capability of these mutants to spread from cell to cell by measuring the diameter of plaques formed in L929 fibroblast monolayers after 3 days of infection in the presence of a low concentration of gentamicin. As indicated in (Figure 5A), no visible plaques were found from the cells infected with the avirulent $\Delta h l y$ strain. Moreover, the compromised cell-to-cell spreading of the $\Delta h l y$ strain was restored

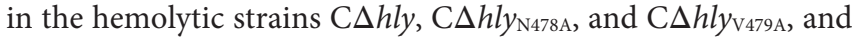
also in the non-hemolytic strain $\mathrm{C} \Delta h l_{\mathrm{N}_{\mathrm{N} 48 \mathrm{AV} 479 \mathrm{~A}}}$ (Figure 5A). Interestingly, these complemented strains, which exhibited the same spreading efficiency, showed a slight defect in terms of their plaque diameters, compared with the wild-type EGD-e strain, indicating that their compromised spreading ability was not fully complemented. Thus, the results suggest that L. monocytogenes expressing $\mathrm{LLO}_{\mathrm{N} 487 \mathrm{~V} 479}$ is not defective in cell-to-cell spreading. This was further confirmed in an actin-tail formation assay where the LLO mutant strains were able to associate with F-actin and formed long actin tails with an efficiency that was comparable to that of the wild-type EGD-e strain and the complemented strain $\mathrm{C} \Delta$ hly in human epithelial Caco- 2 cells (Figure 5B), while deletion of $h l y$ completely compromised the capability to spread from cell to cell, as expected (Figure 5B). Therefore, we conclude that
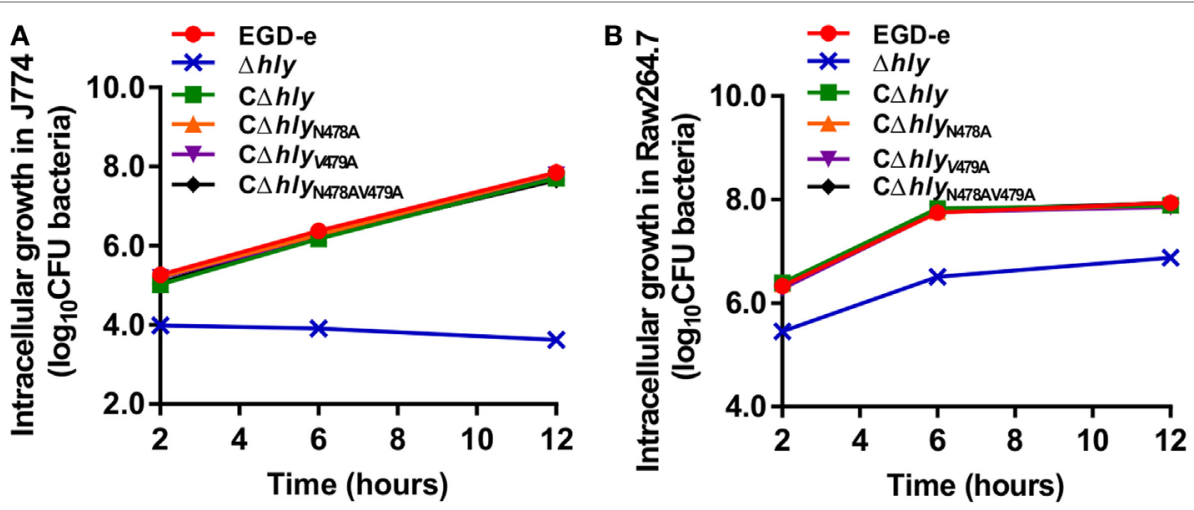

FIGURE 4 | Intracellular growth of Listeria monocytogenes strains producing the indicated listeriolysin O proteins in murine-derived J774 and RAW264.7 macrophages. Gentamicin ( $50 \mu \mathrm{g} / \mathrm{mL}$ ) was added 0.5 h postinfection. The $\mathbf{J} 774$ (A) and RAW264.7 (B) cells infected with the L. monocytogenes wild-type EGD-e

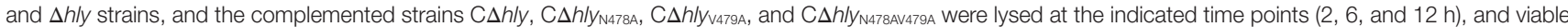
bacteria were serially plated on brain-heart infusion agar plates. The number of recovered bacteria able to invade cells and survive are expressed as means \pm SDs for each strain. 

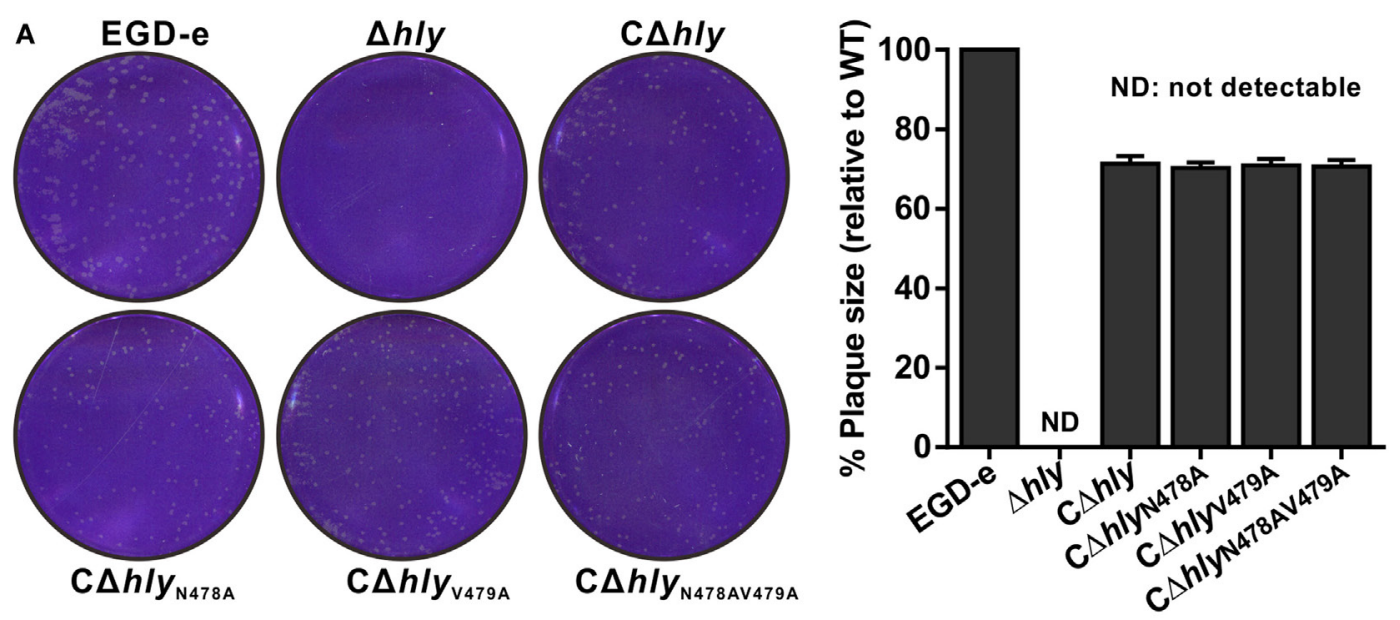

B

EGD-e
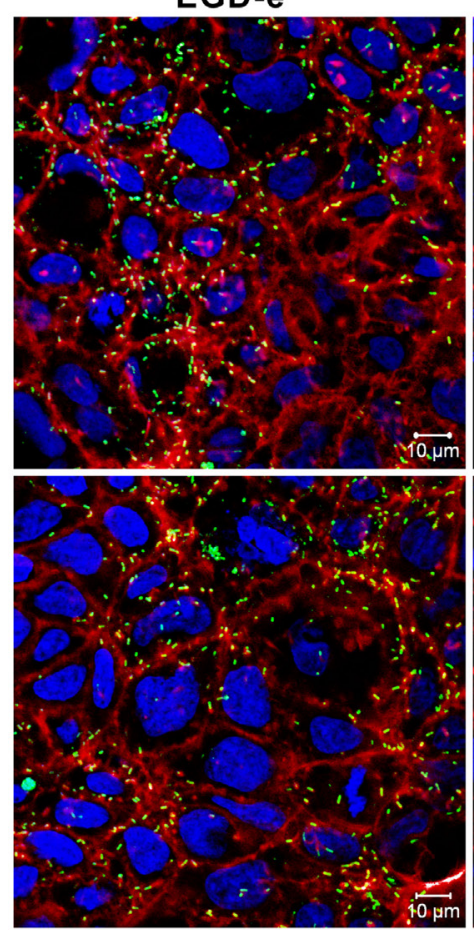

$\mathrm{C} \Delta h / y_{\mathrm{N} 478 \mathrm{~A}}$
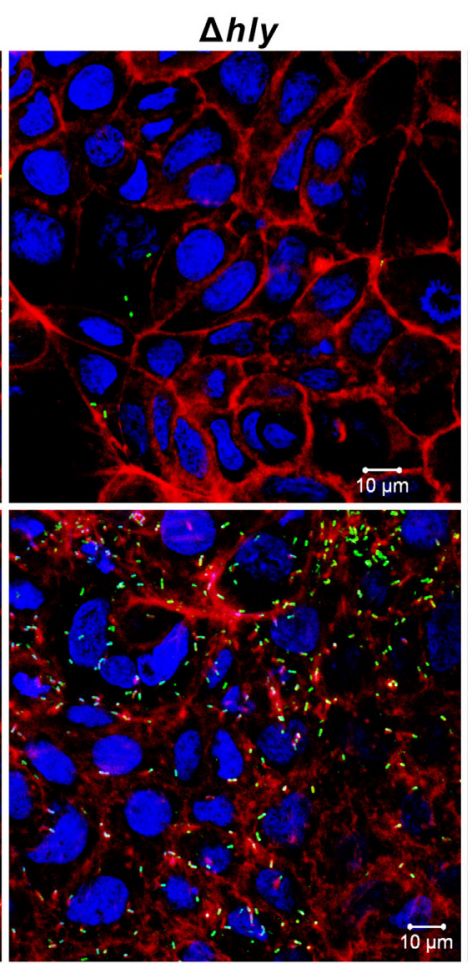

$C \Delta h / y_{\mathrm{V} 479 \mathrm{~A}}$

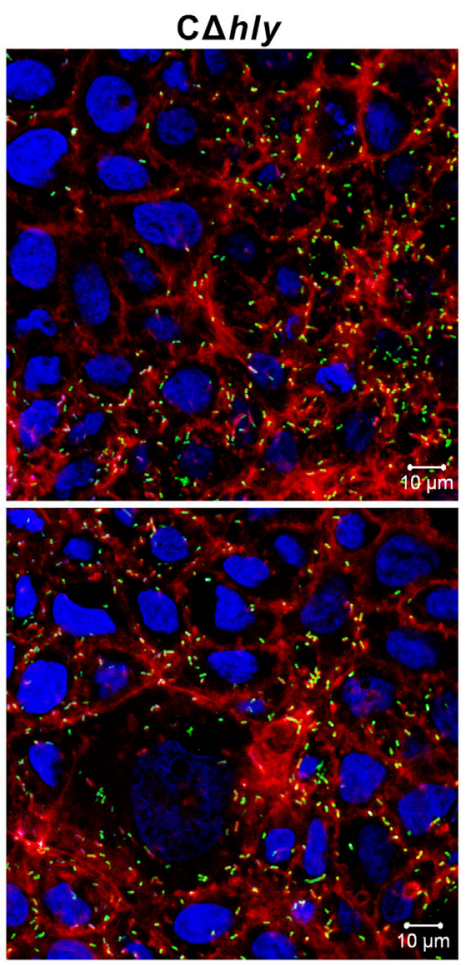

$C \Delta h / y_{\text {N478AV479A }}$

FIGURE 5 | Listeria monocytogenes expressing LLO ${ }_{N 487 v 479}$ is not defective in cell-to-cell spreading. (A) Plaque sizes formed by the indicated L. monocytogenes mutants in L929 cell monolayers as a percentage of the plaque size formed by wild-type bacteria. Following bacterial internalization, gentamicin was added to a concentration of $10 \mu \mathrm{g} / \mathrm{mL}$ as indicated. The values shown represent the means of three independent experiments, and the error bars indicate the SDs. (B) Actin tail formation in Caco-2 cells infected with L. monocytogenes strains $6 \mathrm{~h}$ postinoculation. Bacteria were detected with anti-Lm (green), and bacteria actin tails and host actin were detected using phalloidin (red), while the cell nucleus was labeled with DAPI (blue). The scale bar is $10 \mu \mathrm{m}$. The high-magnification images displayed at the bottom of each image show F-actin (red), bacteria (green), and nuclei (blue).

$\mathrm{LLO}_{\mathrm{N} 487 \mathrm{~V} 479}$ is fully capable of mediating cell-to-cell spreading and escape from the double-membraned vesicle.

\section{DISCUSSION}

The pore-forming protein LLO is a primary determinant of L. monocytogenes pathogenesis that is important for bacterial vacuolar escape into the host cytosol. Tight restriction of its activity in the internalization vacuole appears to be important for infection. Undoubtedly, uncontrolled expression of LLO could lead to perforation of organelles and the host plasma membrane from the inside of the cell, causing cell death and destruction of the L. monocytogenes intracellular niche, thereby exposing the bacteria to the host immune system $(8,14)$. Various mechanisms 
responsible for tightly restricting the activity of LLO within the host cytoplasm have been investigated, such as its ubiquitylation and proteasomal degradation (22). The best studied strategy, however, is its sensitivity to $\mathrm{pH}$ and temperature. Replacement of LLO by $\mathrm{pH}$-insensitive CDCs such as PFO from Clostridium perfringens or anthrolysin $\mathrm{O}$ from Bacillus anthracis allows phagosomal escape of $L$. monocytogenes, but leads to decreased infection $(17,23)$. In fact, the cytolytic activity of LLO does not correlate strictly with the capability of Listeria to escape from the vacuole. In this study, for the first time, we identified a novel mutant, $\mathrm{LLO}_{\mathrm{N} 478 \mathrm{AV} 479 \mathrm{~A}}$, which has barely detectable hemolytic activity, but which escaped, grew intracellularly, and spread cell-to-cell with the same efficiency as a strain secreting wildtype LLO. However, like bacteria lacking LLO, L. monocytogenes strains synthesizing $\mathrm{LLO}_{\mathrm{N} 478 \mathrm{AV} 479 \mathrm{~A}}$ were completely attenuated in virulence in mice. Thus, the results strongly suggest that these two residues at the C-terminus of LLO are key sites that are required for the hemolytic activity of LLO and essential for bacterial pathogenicity in mice, but they are not necessary for L. monocytogenes intracellular survival and cell-to-cell spreading.

The stability of LLO in the host cell cytosol is impacted by proteolytic degradation mechanisms that affect the ability of L. monocytogenes to cause infection. While sufficient levels of LLO are required to infect host cells and promote cell-to-cell spreading, abnormally high levels of LLO are linked to cellular toxicity and clearance of extracellular bacteria by innate immune mechanisms (24). Therefore, we firmly believe that the hemolytic activity and cytotoxicity of LLO must be limited to the lowest level to establish a successful infection within host cells. To achieve this, L. monocytogenes has evolved multiple mechanisms to finely modulate the cytolytic activity of LLO. L. monocytogenes expressing PFO was significantly impaired in its ability to grow intracellularly because the secreted PFO permeabilizes the host cell and allow gentamicin into the cell to kill intracellular bacteria. However, bacteria expressing mutated PFOs (T490I, G461D, and $\mathrm{R} 468 \mathrm{~K}$ ), which have very low or undetectable hemolytic activity, were still capable of escaping from the phagocytic vacuole of macrophages, while their intracellular growth was slightly slower than that of a wild-type strain $(17,18)$. In contrast, previous studies have shown that deletion of the N-terminal PEST-like sequence does not affect LLO hemolytic activity, but it does cause a 1,000-fold decrease in intracellular growth and attenuate bacterial virulence, which is mainly ascribed to the fact that infection of host cells with LLO $\triangle$ PEST-producing bacteria resulted in $90 \%$ of the maximal LDH release, compared with only $2 \%$ for wild-type bacteria. More importantly, bacteria synthesizing the PFO protein fused with the PEST motif can replicate intracellularly and are much less toxic to their host macrophages than bacteria producing the PFO protein without the PEST sequence, indicating that this motif restricts LLO activity to the host cell vacuole, thereby preserving the intracellular niche of L. monocytogenes (12). However, one puzzling observation showed that an LLO $_{\text {L461T }}$ mutant, which displays high activity at neutral $\mathrm{pH}$, still requires acidification of the vacuole to promote Listeria escape, suggesting the involvement of other factors in conjunction with LLO (25). In the present study, we demonstrated that the hemolytic activity of L. monocytogenes expressing a novel mutated LLO (N478AV479A) was completely impaired, but the bacteria were still able to grow intracellularly with a comparable efficiency to that of bacteria expressing wild-type LLO. Together with previously published data, these findings firmly support the view that L. monocytogenes has evolved multiple sophisticated mechanisms to minimize harm to host cells by regulating the activity of LLO. To establish a successful infection and achieve maximal virulence, this pathogen must maintain an equilibrium between producing LLO that is sufficiently cytolytic to escape from the vacuole, yet not overly toxic to infected host cells (25). LLO also has functions that are not linked to its pore-forming activity. Importantly, LLO activity is not unrestricted. Otherwise, host cells would not be able to survive infection by hundreds of bacteria, which is observed routinely. Instead, LLO activity is highly regulated by both $L$. monocytogenes and host cellular processes.

The $\mathrm{LLO}_{\mathrm{N} 478 \mathrm{AV} 479 \mathrm{~A}}$ mutant was capable of mediating vacuolar escape, growing intracellularly, and spreading cell-to-cell with an efficiency close to that of the wild-type strain. Moreover, the cytotoxic level of this mutant was very similar to that of the wild-type strain, indicating that this mutant form of LLO was toxic to the host cell at a normal level and, thus, was able to grow intracellularly both in epithelial cells and murine macrophages. Based on these results, we hypothesized that the virulence of the $\operatorname{LLO}_{\mathrm{N} 478 \mathrm{AV} 479 \mathrm{~A}}$ mutant would be comparable to that of its parent strain expressing wild-type LLO. Surprisingly, this mutant strain was completely non-virulent in mice, as was same the strain lacking LLO. A possible explanation for this result is that while the absence of the pore-forming ability of LLO may be an important protective mechanism, LLO may also have other properties that govern its function within a vacuole during host infection. Importantly, L. monocytogenes is able to infect both phagocytic and nonphagocytic cells, which results in potent innate and adaptive immune responses in an infected host that are required for the clearance of the organism (26). This ability to efficiently induce diverse, complex immune responses using multiple, simultaneous, and integrated mechanisms of action underlies the development of this bacterium as an antigen delivery vector to induce protective cellular immunity against cancer or viral infection (27). L. monocytogenes infection has been long known to also induce type I interferons (IFNs), IFN- $\alpha$ and IFN- $\beta$, which are usually associated with antiviral immune responses and essential for the immune system to clear many viral pathogens. In contrast to IFN- $\gamma$, type I IFNs are beneficial to Listeria infection (28-30). Induction of type I IFNs by L. monocytogenes requires escape of intracellular bacteria into the cytosol (31). Therefore, the highly attenuated L. monocytogenes mutants we identified were still capable of escaping into the cytosol, growing intracellularly, and inducing type I IFNs, potentially making these bacteria a promising tool for protecting against viral infection. However, L. monocytogenes has been shown to harness its ability to deliver foreign antigens efficiently to both the major histocompatibility class I and II presentation machinery and induce robust T-cell responses to Listeria-delivered antigens, thus making it a powerful vaccine vector for tumor immunotherapy. In a therapeutic setting, detoxified LLO with a completely impaired cytolytic activity 
acts as a potent adjuvant, enabling it to serve as a powerful antigen fusion partner to create antigen-adjuvant proteins (27). More recently, several studies have shown that tumor antigens genetically fused to detoxified LLO exhibit enhanced ubiquitin-proteasome-mediated processing and presentation by antigen-presenting cells for the activation of antigen-specific cytotoxic T lymphocytes, and stimulated the necessary proinflammatory responses for effective antitumor adaptive immune responses $(32,33)$. In the present study, we identified a novel, nontoxic LLO (N478AV479A) that still enables the bacteria to efficiently mediate vacuolar escape and survive intracellularly, while exhibiting attenuated virulence, which could provide a new adjuvant fusion partner with a cognate antigen for tumor immunotherapy. In conclusion, we have shown that residues N478 and V479 are required for the cytolytic activity of LLO and essential for L. monocytogenes pathogenicity in mice, but not for intracellular infection, which will provide new insights that increase our understanding of the current and future development of Listeria-based antigen delivery vectors to induce protective cellular immunity against tumors or infections.

\section{MATERIALS AND METHODS}

\section{Bacterial Strains, Plasmids, and Culture Conditions}

Listeria monocytogenes EGD-e was used as the wild-type strain. E. coli $\mathrm{DH} 5 \alpha$ was employed for cloning experiments and as the host strain for plasmids pET30a(+) (Merck, Darmstadt, Germany), pIMK2 and pKSV7. E. coli Rosetta (DE3) was used for prokaryotic protein expression. Listeria strains were cultured in brain-heart infusion (BHI) medium (Oxoid, Hampshire, England). E. coli strains were grown at $37^{\circ} \mathrm{C}$ in Luria-Bertani broth (LB) (Oxoid). Stock solutions of ampicillin $(50 \mathrm{mg} / \mathrm{mL})$, erythromycin $(50 \mathrm{mg} / \mathrm{mL})$, kanamycin $(50 \mathrm{mg} / \mathrm{mL})$, or chloramphenicol $(50 \mathrm{mg} / \mathrm{mL})$ were added to media where appropriate. All chemicals were obtained from Sangon Biotech (Shanghai, China), Merck or Sigma-Aldrich (St. Louis, MO, USA) and were of the highest purity available. All primers used in this study are listed in Table S1 in Supplementary Material.

\section{L. monocytogenes Gene In-Frame Deletion}

The temperature-sensitive pKSV7 shuttle vector was used for creating mutations from $L$. monocytogenes strain EGD-e background. Genomic DNA was extracted as described previously $(34,35)$. A homologous recombination strategy with SOE-PCR procedure was used for in-frame deletion to construct hly deletion mutant (36). Specifically, the DNA fragments containing homologous arms upstream and downstream of hly were obtained by PCR amplification of EGD-e DNA templates using the SOE primer pairs $h l y$-a/hly-b and $h l y$-c/hly-d (Table S1 in Supplementary Material). The obtained fragment was then cloned into the vector pKSV7 and electroporated into the competent EGD-e cells. Transformants were grown at a non-permissive temperature $\left(41^{\circ} \mathrm{C}\right)$ in $\mathrm{BHI}$ medium containing chloramphenicol to promote chromosomal integration and the recombinants were passaged successively in $\mathrm{BHI}$ without antibiotics at a permissive temperature $\left(30^{\circ} \mathrm{C}\right)$ to enable plasmid excision and curing (37). The recombinants were identified as chloramphenicol-sensitive colonies, and the mutagenesis was further confirmed by PCR and DNA sequencing.

\section{Complementation of Gene Deletion Mutant}

To complement the L. monocytogenes $\Delta h l y$ strain, we constructed a complemented strain by using the integrative plasmid pIMK2. The complete open reading frame (ORF) of hly along with its native promoter region was amplified using the primer pairs $\mathrm{C} \Delta h l y$-e/C $\Delta h l y$-f (Table S1 in Supplementary Material) and cloned into pIMK2 following restriction to cut off the $P_{\text {help }}$ region with enzymes. The resulting plasmid was then electroporated into L. monocytogenes $\Delta$ hly strain. Regenerated cells were plated on BHI agar containing kanamycin $(50 \mu \mathrm{g} / \mathrm{mL})$. The complemented strain was designated as $\mathrm{C} \Delta h l y$.

\section{Overexpression and Purification of His- Tagged LLO Proteins from E. coli}

Recombinant proteins used in this study were expressed as fusion proteins to the N-terminal His-tag using pET30a(+) as the expression vector (38). E. coli Rosetta (DE3) was used as the expression host. The full-length ORF of the interest gene from EGD-e genome was amplified with the primer pair (Table S1 in Supplementary Material) and then inserted into the pET30a(+) vector, and finally transformed into Rosetta competent cells. E. coli cells harboring the recombinant plasmids were grown in $500 \mathrm{~mL} \mathrm{LB}$ medium supplemented with $50 \mu \mathrm{g} / \mathrm{mL}$ kanamycin at $37^{\circ} \mathrm{C}$ until the cultures reached $0.8-1.0$ at $\mathrm{OD}_{600 \mathrm{~nm}}$. Isopropyl $\beta$-D-1-thiogalactopyranoside (IPTG) was then added to a final concentration of $0.4 \mathrm{mM}$ to induce expression of the recombinant proteins for additional $4 \mathrm{~h}$ under the optimized conditions. The His-tagged fusion proteins were purified using the nickel-chelated affinity column chromatography.

\section{Preparation of Polyclonal Antibodies against the Recombinant Proteins}

Purified recombinant protein was used to raise polyclonal antibodies in New Zealand white rabbits according to a standard protocol (39). Briefly, rabbits were initially immunized via subcutaneous injection of $500 \mu \mathrm{g}$ protein with an equal volume of Freund's complete adjuvant (Sigma). After 2 weeks, rabbits were boosted by subcutaneous injection of $250 \mu \mathrm{g}$ protein each in incomplete Freund's adjuvant (Sigma) three times at 10-day intervals. Rabbits were bled $\sim 10$ days after the last injection.

\section{Site-Directed Mutagenesis}

Single site-directed mutants (N478A and V479A) and the double site-directed mutant (N478AV479A) of LLO were generated using the original vector template, pET30a-LLO or pIMK2-LLO, and the QuikChange Site-Directed Mutagenesis kit (Agilent Technologies, Palo Alto, CA, USA) with the primer pairs described in Table S1 in Supplementary Material. Template DNA was removed via digestion with DpnI (Toyobo Co., Osaka, 
Japan) for $2 \mathrm{~h}$ at $37^{\circ} \mathrm{C}$. All mutant constructs were sequenced to ensure that only the desired single mutations had been incorporated correctly. The mutant constructs based on the plasmid pET30a-LLO were transformed into E. coli Rosetta competent cells and the corresponding mutant proteins were designated as $\mathrm{LLO}_{\mathrm{N} 478 \mathrm{~A}}, \mathrm{LLO}_{\mathrm{V} 479 \mathrm{~A}}$, and $\mathrm{LLO}_{\mathrm{N} 478 \mathrm{AV} 479 \mathrm{~A}}$ accordingly, and expressed, purified as described above. For mutant complemented strains, the mutant constructs based on the plasmid pIMK2-LLO were electroporated into L. monocytogenes $\Delta h l y$ competent cells, and

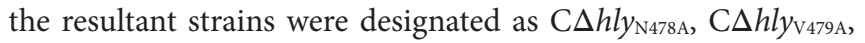
and $\mathrm{C} \Delta h l_{\mathrm{N} 478 \mathrm{AV} 479 \mathrm{~A}}$, respectively.

\section{Growth Analysis of L. monocytogenes in BHI Broth}

Listeria monocytogenes wild-type strain EGD-e, mutant strain $\Delta h l y$, complemented strains $\mathrm{C} \Delta h l y, \mathrm{C} \Delta h l y_{\mathrm{N} 478 \mathrm{~A}}, \mathrm{C} \Delta h l y_{\mathrm{V} 479 \mathrm{~A}}$, and $\mathrm{C} \Delta h l_{\mathrm{N} 478 \mathrm{AV} 479 \mathrm{~A}}$ were grown overnight at $37^{\circ} \mathrm{C}$ in $\mathrm{BHI}$ broth with shaking. Cultures were collected by centrifugation at $5,000 \times g$ at $4^{\circ} \mathrm{C}$, washed once in phosphate-buffered saline (PBS) $(10 \mathrm{mM}$, $\mathrm{pH}$ 7.4) and initial $\mathrm{OD}_{600 \mathrm{~nm}}$ adjusted to 1.0. Bacteria were diluted $(1: 100)$ in fresh $\mathrm{BHI}$ broth, and incubated at $37^{\circ} \mathrm{C}$ for $12 \mathrm{~h}$. Kinetic growth was measured $\left(\mathrm{OD}_{600 \mathrm{~nm}}\right)$ at $1-\mathrm{h}$ interval.

\section{LLO-Mediated Hemolytic Activity Measurement}

Measurement of LLO-associated hemolytic activity was done as described previously (40). L. monocytogenes wild-type and mutant strains were grown for $16 \mathrm{~h}$ with shaking in BHI broth at $37^{\circ} \mathrm{C}$. All cultures were adjusted to $\mathrm{OD}_{600 \mathrm{~nm}}$ of 1.0 before supernatants were collected. Hemolytic activity was measured based on lysis of sheep red blood cells (SRBCs) of secreted LLO from culture supernatants. Specifically, culture supernatant $(50 \mu \mathrm{L})$ was diluted in hemolysis buffer $(10 \mathrm{mM}$ PBS, pH 5.5 or $7.4,150 \mathrm{mM} \mathrm{NaCl}, 1 \mathrm{mM}$ DTT) in final volumes of $50 \mu \mathrm{L}$ and equilibrated to $37^{\circ} \mathrm{C}$ for $10 \mathrm{~min}$. Next, $50 \mu \mathrm{L}$ PBS-washed intact SRBCs (5\%) were added to each sample and incubated at $37^{\circ} \mathrm{C}$ for $30 \mathrm{~min}$. Samples were centrifuged and supernatants analyzed for hemoglobin absorption at $550 \mathrm{~nm}$. For hemolysis determination of recombinant proteins, purified LLO or its mutant protein $\left(\mathrm{LLO}_{\mathrm{N} 478 \mathrm{~A}}, \mathrm{LLO}_{\mathrm{V} 479 \mathrm{~A}}\right.$, and $\left.\mathrm{LLO}_{\mathrm{N} 478 \mathrm{AV} 479 \mathrm{~A}}\right)$ expressed in E. coli was serially diluted in hemolysis buffer, then mixed with an equal volume of 5\% SRBC and the hemolytic activity determined as described above. The values corresponding to the reciprocal of the dilution of culture supernatant required to lyse $50 \%$ of HRBCs were used to compare the hemolytic activities in the different supernatants. Erythrocytes incubated with 1\% Triton X-100 or PBS served to determine the maximum (100\%) and minimum (0\%) hemolytic activity, respectively.

\section{Cell Fractionation and Protein Localization of LLO}

Western blotting was employed to analyze the changes in expression of LLO. Bacterial overnight cultures of L. monocytogenes were diluted into $200 \mathrm{~mL}$ fresh $\mathrm{BHI}$ broth, and bacteria were grown to the stationary phase. For secreted proteins isolation: the fractionation procedure was described by Lenz and Portnoy
(41), with minor modifications. Briefly, the bacteria cells were pelleted by centrifugation at $13,000 \mathrm{~g}$ for $20 \mathrm{~min}$ at $4^{\circ} \mathrm{C}$, and the resulting culture supernatant collected and then filtered through a $0.22 \mu \mathrm{m}$ polyethersulfone membrane filter (Thermo Fisher Scientific, Lafayette, LA, USA). Trichloroacetic acid (TCA) was added to the supernatant to reach a final concentration of $10 \%$ TCA. Proteins were TCA-precipitated on ice overnight and washed with ice-cold acetone. The washed precipitates of supernatant proteins were re-suspended in SDS-PAGE sample buffer (5\% SDS, 10\% glycerol, and $50 \mathrm{mM}$ Tris-HCl, pH 6.8). Samples were boiled for $6 \mathrm{~min}$ and stored at $-20^{\circ} \mathrm{C}$ before electrophoresis. For total cell proteins isolation: the previous method was applied (42). Specifically, the bacterial pellets were re-suspended in $1 \mathrm{~mL}$ of extraction solution (2\% Triton X-100, 1\% SDS, $100 \mathrm{mM} \mathrm{NaCl}$, $10 \mathrm{mM}$ Tris- $\mathrm{HCl}, 1 \mathrm{mM}$ EDTA, $\mathrm{pH}$ 8.0). One gram of glass beads (G8772, Sigma-Aldrich) was added and samples lysed by using the homogenizer Precelly 24 (Bertin, Provence, France) at $6,000 \mathrm{rpm}$ for $30 \mathrm{~s}$ with intermittent cooling for $30 \mathrm{~s} \mathrm{(3} \mathrm{cycles} \mathrm{in}$ total) and then centrifuged at 12,000 rpm for $15 \mathrm{~min}$. Supernatant was retained as the whole cell extract. The method for total cell proteins isolation was used as described above. Protein samples were separated through a $12 \%$ SDS-PAGE and immunoblotted with $\alpha$-LLO or $\alpha$-GAPDH antisera. GAPDH was used as an internal control.

\section{Virulence in the Mouse Model}

The L. monocytogenes wild-type strain EGD-e, mutant strain $\Delta h l y$, and complemented strains $\mathrm{C} \Delta h l y, \mathrm{C} \Delta h l y_{\mathrm{N} 478 \mathrm{~A}}, \mathrm{C} \Delta h l_{\mathrm{V} 479 \mathrm{~A}}$,

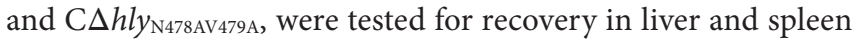
sections of ICR mice (female, 18-22 g, purchased from Zhejiang Academy of Medical Sciences, Hangzhou, China) as previously described (39). The mice ( 8 per group) were injected intraperitoneally with $\sim 10^{6} \mathrm{CFU}$ of each strain. At 24 and $48 \mathrm{~h}$ postinfection, mice were sacrificed, and livers and spleens removed and individually homogenized in $10 \mathrm{mM}$ PBS ( $\mathrm{pH}$ 7.4). Surviving Listeria cells were enumerated by plating serial dilutions of homogenates on BHI agar plates. Results were expressed as means \pm SD of recovery bacterial number $\left(\log _{10} \mathrm{CFU}\right)$ per organ for each group. For animal survival experiments, mice injected intraperitoneally with $1 \times 10^{7} \mathrm{CFU}$ listeria were monitored for up to 7 days after infection. Survival curves were calculated by using the Kaplan-Meier method and differences in survival were determined by using the Log-rank test.

\section{Proliferation in RAW264.7 Macrophages}

Bacteria survival or proliferation murine macrophages RAW264.7 was conducted as previously described (43). Stationary L. monocytogenes wild-type strain EGD-e, mutant $\Delta h l y$, complemented strains $\mathrm{C} \Delta h l y, \mathrm{C} \Delta h l y_{\mathrm{N} 478 \mathrm{~A}}, \mathrm{C} \Delta h l y_{\mathrm{V} 479 \mathrm{~A}}$, and $\mathrm{C} \Delta h l y_{\mathrm{N} 478 \mathrm{AV} 479 \mathrm{~A}}$ cells at $37^{\circ} \mathrm{C}$ in $\mathrm{BHI}$ were washed and re-suspended in $10 \mathrm{mM}$ PBS ( $\mathrm{pH}$ 7.4). Monolayers of RAW264.7 cells, cultured in Dulbecco's modified Eagle medium (DMEM, Thermo Fisher Scientific) containing 10\% fetal bovine serum (FBS, GE Healthcare Hyclone, Logan, UT, USA) were infected with the above strains for $60 \mathrm{~min}$ with multiplicity of infection (MOI) at 10:1. For adhesion, cells were lysed after being washed three times with PBS. For estimation of invasion, cells were washed with PBS after $1 \mathrm{~h}$ infection 
and incubated for an additional hour in DMEM containing gentamicin at $50 \mu \mathrm{g} / \mathrm{mL}$ for $30 \mathrm{~min}$ to kill extracellular bacteria. Infected cells were lysed by adding $1 \mathrm{~mL}$ of ice-cold sterile distilled water. The lysates were 10 -fold diluted for enumeration of viable bacteria on BHI agar plates that were considered as the $0 \mathrm{~h}$ numbers invading into the cells. For intracellular proliferation, cells were subjected to further incubation for 6,12 , or $18 \mathrm{~h}$ in $5 \%$ $\mathrm{CO}_{2}$ at $37^{\circ} \mathrm{C}$. Viable bacteria were enumerated by serial dilution and colony counting on BHI agar plates.

\section{Intracellular Growth in J774 Macrophages}

Intracellular growth was performed as described previously for monolayers of J774 macrophages (44). Specifically, overnight cultures of $L$. monocytogenes strains were washed three times and re-suspended in PBS, and then J774 cells infected with bacteria at an MOI of 0.05 . Following 30 min incubation, cells were washed, and extracellular bacteria were killed by adding complete medium containing $50 \mu \mathrm{g} / \mathrm{mL}$ of gentamicin for an additional $30 \mathrm{~min}$ incubation. At 2, 6, or $12 \mathrm{~h}$ postinfection, cells were washed with PBS and finally lysed in ice-cold sterile distilled water. The number of viable intracellular L. monocytogenes cells was calculated by serial dilution and colony counting on $\mathrm{BHI}$ agar plates as mentioned above.

\section{Plaque Assay}

The plaque assay was carried out by conventional methods $(45,46)$. Briefly, mouse L929 fibroblast cell monolayers were maintained in high-glucose DMEM medium (Thermo Fisher Scientific) plus FBS (Hyclone) and $2 \mathrm{mM}$ L-glutamine. Cells were plated at $1 \times 10^{6}$ cells per well in a six-well dish and infected at an MOI of 1:50 with L. monocytogenes at $37^{\circ} \mathrm{C}$ with $5 \% \mathrm{CO}_{2}$ for $1 \mathrm{~h}$. Extracellular bacteria were killed with $100 \mu \mathrm{g} /$ $\mathrm{mL}$ gentamicin, and the cells washed three times with $10 \mathrm{mM}$ PBS (pH 7.4) and then overlaid with $3 \mathrm{~mL}$ of medium plus $0.7 \%$ agarose and $10 \mu \mathrm{g} / \mathrm{mL}$ gentamicin. Following a $72-\mathrm{h}$ incubation at $37^{\circ} \mathrm{C}$, cells were fixed with paraformaldehyde (4\% in PBS for $20 \mathrm{~min}$ ) and stained with crystal violet. The diameter of plaques was measured by Adobe Photoshop software for each strain. The plaque size of wild-type strain EGD-e was set as 100\% and data are shown as means \pm SDs.

\section{Phagosomal Escape Assay in Caco-2 Cells}

Phagosomal escape assay was conducted according to the previous work (39). Specifically, human intestinal epithelial Caco-2 cells were infected at MOI of $10: 1$ at $37^{\circ} \mathrm{C}$ with $5 \% \mathrm{CO}_{2}$ for $1 \mathrm{~h}$. Extracellular bacteria were then killed with $50 \mu \mathrm{g} / \mathrm{mL}$ gentamicin for $1 \mathrm{~h}$ and incubated for an additional $6 \mathrm{~h}$. Cells were washed gently with PBS (10 mM, pH 7.4), fixed with $4 \%$ paraformaldehyde and then permeabilized with $0.5 \%$ Triton $\mathrm{X}-100$. The bacterial cells were stained with polyclonal antibodies to L. monocytogenes for $1 \mathrm{~h}$ at $37^{\circ} \mathrm{C}$, washed twice with PBS, and probed with Alexa Fluor 488-conjugated donkey anti-rabbit antibody (Santa Cruz) for $1 \mathrm{~h}$ at $37^{\circ} \mathrm{C}$. F-actin was then stained with phalloidin-Alexa Fluor 568 (Thermo Fisher Scientific). DAPI (4',6-diamidino-2-phenylindole) (Thermo Fisher Scientific) was used to stain the nuclei. Actin tails recruited by the bacteria were visualized under a ZEISS LSM510 confocal microscope (Zeiss Germany, Oberkochen, Germany).

\section{Cytotoxicity Detection}

Cytotoxicity was detected based on LDH release from J774 macrophages following bacterial infection by using the CytoTox 96 non-radioactive cytotoxicity assay kit according to the manufacturer's instructions (Promega, WI, USA), as previously described by Decatur and Portnoy (12). Overnight cultured $L$. monocytogenes was deposited onto J774 cells at a MOI of 10 at $37^{\circ} \mathrm{C}$ with $5 \% \mathrm{CO}_{2}$ for $30 \mathrm{~min}$, after which the culture medium with or without $50 \mu \mathrm{g} / \mathrm{mL}$ gentamicin was added. To determine maximum $\mathrm{LDH}$ release, $100 \mu \mathrm{L}$ of lysis buffer was added to triplicate infected wells $45 \mathrm{~min}$ prior to $\mathrm{LDH}$ measurement. At the indicated infection times $(2,4$, and $6 \mathrm{~h})$, cells were centrifuged at $250 \times g$ for $5 \mathrm{~min}$, and the supernatant was removed and used for the LDH assay. The supernatant was incubated for 30 min with $50 \mu \mathrm{L}$ substrate mix prior to the addition of $50 \mu \mathrm{L}$ stop solution. Absorption at $490 \mathrm{~nm}$ was then measured using the Micro-plate reader Synergy H1 (BioTek Solutions, Inc., Santa Barbara, CA, USA). The experimental design included three wells containing only DMEM to account for background absorption as well as three wells containing uninfected J774 cells to measure spontaneous LDH release. After background correction, the percent cytotoxicity was calculated as follows: cytotoxicity $\%=[($ experimental $\mathrm{LDH}$ release - spontaneous $\mathrm{LDH}$ release)/(maximum $\mathrm{LDH}$ release - spontaneous $\mathrm{LDH}$ release $)] \times 100$.

\section{Statistical Analysis}

All experiments were repeated at least three times. Data were analyzed using the two-tailed homoscedastic Student's $t$-test. Differences with $P$-values $<0.05$ were considered as statistically significant.

\section{ETHICS STATEMENT}

All animal care and use protocols were performed in accordance with the Regulations for the Administration of Affairs Concerning Experimental Animals approved by the State Council of People's Republic of China. The protocol was approved by the Institutional Animal Care and Use Committee of Zhejiang A\&F University (Permit Number: ZJAFU/IACUC_2011-10-25-02). All the Listeria monocytogenes-involved experiments in our study were conducted at Biosafety Level 2 laboratory.

\section{AUTHOR CONTRIBUTIONS}

CC, WF, and HS conceived the study. CC, LJ, TM, JS, HW, XH, $\mathrm{YH}, \mathrm{HY}, \mathrm{CF}$, and FL carried out experiments. CC, YY, ZC, and $\mathrm{HH}$ analyzed data. CC, NF, and HS drafted the manuscript and all authors contributed to this study prepared the final version of the manuscript. All authors read and approved the final manuscript. 


\section{FUNDING}

This work was supported by Initiative Design Project of Agricultural Research of Hangzhou (No. 20162012A07), National Natural Science Foundation of China (Nos. 31770040, 31470179, and 31402215), Zhejiang Provincial Natural Science Foundation (Nos. LY17C180001), and ZAFU talents starting program (No. 2014FR073 and 2015FR007). The funders had

\section{REFERENCES}

1. Vazquez-Boland JA, Krypotou E, Scortti M. Listeria placental infection. MBio (2017) 8(3):e00949-17. doi:10.1128/mBio.00949-17

2. Cajnko MM, Marusic M, Kisovec M, Rojko N, Bencina M, Caserman S, et al. Listeriolysin $\mathrm{O}$ affects the permeability of Caco-2 monolayer in a poredependent and Ca2+-independent manner. PLoS One (2015) 10(6):e0130471. doi:10.1371/journal.pone.0130471

3. Odedina GF, Vongkamjan K, Voravuthikunchai SP. Potential biocontrol agent from Rhodomyrtus tomentosa against Listeria monocytogenes. Nutrients (2015) 7(9):7451-68. doi:10.3390/nu7095346

4. Lety MA, Frehel C, Berche P, Charbit A. Critical role of the N-terminal residues of listeriolysin $\mathrm{O}$ in phagosomal escape and virulence of Listeria monocytogenes. Mol Microbiol (2002) 46(2):367-79. doi:10.1046/j.1365-2958. 2002.03176.x

5. Rolhion N, Cossart P. How the study of Listeria monocytogenes has led to new concepts in biology. Future Microbiol (2017) 12:621-38. doi:10.2217/ fmb-2016-0221

6. Cossart $\mathrm{P}$, Bierne $\mathrm{H}$. The use of host cell machinery in the pathogenesis of Listeria monocytogenes. Curr Opin Immunol (2001) 13(1):96-103. doi:10.1016/ S0952-7915(00)00188-6

7. Ribet D, Cossart P. How bacterial pathogens colonize their hosts and invade deeper tissues. Microbes Infect (2015) 17(3):173-83. doi:10.1016/j. micinf.2015.01.004

8. Hamon MA, Ribet D, Stavru F, Cossart P. Listeriolysin O: the Swiss army knife of Listeria. Trends Microbiol (2012) 20(8):360-8. doi:10.1016/j.tim. 2012.04.006

9. Bayley H. Toxin structure: part of a hole? Curr Biol (1997) 7(12):R763-7. doi:10.1016/S0960-9822(06)00399-X

10. Alouf JE. Pore-forming bacterial protein toxins: an overview. Curr Top Microbiol Immunol (2001) 257:1-14.

11. Koster S, van Pee K, Hudel M, Leustik M, Rhinow D, Kuhlbrandt W, et al. Crystal structure of listeriolysin O reveals molecular details of oligomerization and pore formation. Nat Commun (2014) 5:3690. doi:10.1038/ ncomms4690

12. Decatur AL, Portnoy DA. A PEST-like sequence in listeriolysin O essential for Listeria monocytogenes pathogenicity. Science (2000) 290(5493):992-5. doi:10.1126/science.290.5493.992

13. Schnupf P, Portnoy DA, Decatur AL. Phosphorylation, ubiquitination and degradation of listeriolysin $\mathrm{O}$ in mammalian cells: role of the PEST-like sequence. Cell Microbiol (2006) 8(2):353-64. doi:10.1111/j.1462-5822.2005. 00631.x

14. Glomski IJ, Decatur AL, Portnoy DA. Listeria monocytogenes mutants that fail to compartmentalize listerolysin $\mathrm{O}$ activity are cytotoxic, avirulent, and unable to evade host extracellular defenses. Infect Immun (2003) 71(12): 6754-65. doi:10.1128/IAI.71.12.6754-6765.2003

15. Portman JL, Huang Q, Reniere ML, Iavarone AT, Portnoy DA. Activity of the pore-forming virulence factor listeriolysin $\mathrm{O}$ is reversibly inhibited by naturally occurring S-glutathionylation. Infect Immun (2017) 85(4):e00959-16. doi:10.1128/IAI.00959-16

16. Schuerch DW, Wilson-Kubalek EM, Tweten RK. Molecular basis of listeriolysin O pH dependence. Proc Natl Acad Sci U S A (2005) 102(35):12537-42. doi:10.1073/pnas.0500558102

17. Jones S, Portnoy DA. Characterization of Listeria monocytogenes pathogenesis in a strain expressing perfringolysin $\mathrm{O}$ in place of listeriolysin O. Infect Immun (1994) 62(12):5608-13. no role in design of the study or analysis and interpretation of the data.

\section{SUPPLEMENTARY MATERIAL}

The Supplementary Material for this article can be found online at http://www.frontiersin.org/article/10.3389/fimmu.2017.01439/ full\#supplementary-material.

18. Jones S, PreiterK, Portnoy DA. Conversion of an extracellularcytolysin into a phagosome-specific lysin which supports the growth of an intracellular pathogen. Mol Microbiol (1996) 21(6):1219-25. doi:10.1046/j.1365-2958.1996.00074.x

19. Michel E, Reich KA, Favier R, Berche P, Cossart P. Attenuated mutants of the intracellular bacterium Listeria monocytogenes obtained by single amino acid substitutions in listeriolysin O. Mol Microbiol (1990) 4(12):2167-78. doi:10.1111/j.1365-2958.1990.tb00578.x

20. Farrand AJ, LaChapelle S, Hotze EM, Johnson AE, Tweten RK. Only two amino acids are essential for cytolytic toxin recognition of cholesterol at the membrane surface. Proc Natl Acad Sci U S A (2010) 107(9):4341-6. doi:10.1073/pnas.0911581107

21. Dowd KJ, Farrand AJ, Tweten RK. The cholesterol-dependent cytolysin signature motif: a critical element in the allosteric pathway that couples membrane binding to pore assembly. PLoS Pathog (2012) 8(7):e1002787. doi:10.1371/journal.ppat.1002787

22. Schnupf P, Portnoy DA. Listeriolysin O: a phagosome-specific lysin. Microbes Infect (2007) 9(10):1176-87. doi:10.1016/j.micinf.2007.05.005

23. Wei Z, Schnupf P, Poussin MA, Zenewicz LA, Shen H, Goldfine $H$. Characterization of Listeria monocytogenes expressing anthrolysin $\mathrm{O}$ and phosphatidylinositol-specific phospholipase C from Bacillus anthracis. Infect Immun (2005) 73(10):6639-46. doi:10.1128/IAI.73.10.6639-6646.2005

24. Osborne SE, Brumell JH. Listeriolysin O: from bazooka to Swiss army knife. Philos Trans R Soc Lond B Biol Sci (2017) 372(1726). doi:10.1098/ rstb.2016.0222

25. Glomski IJ, Gedde MM, Tsang AW, Swanson JA, Portnoy DA. The Listeria monocytogenes hemolysin has an acidic $\mathrm{pH}$ optimum to compartmentalize activity and prevent damage to infected host cells. J Cell Biol (2002) 156(6):1029-38. doi:10.1083/jcb.200201081

26. Wood LM, Paterson Y. Attenuated Listeria monocytogenes: a powerful and versatile vector for the future of tumor immunotherapy. Front Cell Infect Microbiol (2014) 4:51. doi:10.3389/fcimb.2014.00051

27. Rothman J, Paterson Y. Live-attenuated Listeria-based immunotherapy. Expert Rev Vaccines (2013) 12(5):493-504. doi:10.1586/erv.13.34

28. Auerbuch V, Brockstedt DG, Meyer-Morse N, O'Riordan M, Portnoy DA. Mice lacking the type I interferon receptor are resistant to Listeria monocytogenes. J Exp Med (2004) 200(4):527-33. doi:10.1084/jem.20040976

29. Carrero JA, Calderon B, Unanue ER. Type I interferon sensitizes lymphocytes to apoptosis and reduces resistance to Listeria infection. J Exp Med (2004) 200(4):535-40. doi:10.1084/jem.20040769

30. O'Connell RM, Saha SK, Vaidya SA, Bruhn KW, Miranda GA, Zarnegar B, et al. Type I interferon production enhances susceptibility to Listeria monocytogenes infection. J Exp Med (2004) 200(4):437-45. doi:10.1084/jem. 20040712

31. McCaffrey RL, Fawcett P, O’Riordan M, Lee KD, Havell EA, Brown PO, et al. A specific gene expression program triggered by Gram-positive bacteria in the cytosol. Proc Natl Acad Sci U S A (2004) 101(31):11386-91. doi:10.1073/ pnas.0403215101

32. Peng X, Treml J, Paterson Y. Adjuvant properties of listeriolysin O protein in a DNA vaccination strategy. Cancer Immunol Immunother (2007) 56(6):797-806. doi:10.1007/s00262-006-0240-9

33. Wallecha A, Wood L, Pan ZK, Maciag PC, Shahabi V, Paterson Y. Listeria monocytogenes-derived listeriolysin $\mathrm{O}$ has pathogen-associated molecular pattern-like properties independent of its hemolytic ability. Clin Vaccine Immunol (2013) 20(1):77-84. doi:10.1128/CVI.00488-12

34. Cheng C, Chen J, Fang C, Xia Y, Shan Y, Liu Y, et al. Listeria monocytogenes aguA1, but not aguA2, encodes a functional agmatine deiminase: biochemical 
characterization of its catalytic properties and roles in acid tolerance. J Biol Chem (2013) 288(37):26606-15. doi:10.1074/jbc.M113.477380

35. Cheng C, Yang Y, Dong Z, Wang X, Fang C, Yang M, et al. Listeria monocytogenes varies among strains to maintain intracellular $\mathrm{pH}$ homeostasis under stresses by different acids as analyzed by a high-throughput microplate-based fluorometry. Front Microbiol (2015) 6:15. doi:10.3389/fmicb.2015.00015

36. Monk IR, Gahan CG, Hill C. Tools for functional postgenomic analysis of Listeria monocytogenes. Appl Environ Microbiol (2008) 74(13):3921-34. doi:10.1128/AEM.00314-08

37. Camilli A, Tilney LG, Portnoy DA. Dual roles of plcA in Listeria monocytogenes pathogenesis. Mol Microbiol (1993) 8(1):143-57. doi:10.1111/j. 1365-2958.1993.tb01211.x

38. Cheng C, Dong Z, Han X, Sun J, Wang H, Jiang L, et al. Listeria monocytogenes $10403 \mathrm{~S}$ arginine repressor ArgR finely tunes arginine metabolism regulation under acidic conditions. Front Microbiol (2017) 8:145. doi:10.3389/ fmicb.2017.00145

39. Cheng C, Dong Z, Han X, Wang H, Jiang L, Sun J, et al. Thioredoxin A is essential for motility and contributes to host infection of Listeria monocytogenes via redox interactions. Front Cell Infect Microbiol (2017) 7:287. doi:10.3389/ fcimb.2017.00287

40. Xayarath B, Alonzo F III, Freitag NE. Identification of a peptidepheromone that enhances Listeria monocytogenes escape from host cell vacuoles. PLoS Pathog (2015) 11(3):e1004707. doi:10.1371/journal.ppat.1004707

41. Lenz LL, Portnoy DA. Identification of a second Listeria secA gene associated with protein secretion and the rough phenotype. Mol Microbiol (2002) 45(4):1043-56. doi:10.1046/j.1365-2958.2002.03072.x

42. Ryan S, Begley M, Gahan CG, Hill C. Molecular characterization of the arginine deiminase system in Listeria monocytogenes: regulation and role in acid tolerance. Environ Microbiol (2009) 11(2):432-45. doi:10.1111/j. 1462-2920.2008.01782.x

43. Reddy S, Akgul A, Karsi A, Abdelhamed H, Wills RW, Lawrence ML. The role of Listeria monocytogenes cell wall surface anchor protein LapB in virulence, adherence, and intracellular replication. Microb Pathog (2016) 92:19-25. doi:10.1016/j.micpath.2015.12.012

44. Jones S, Portnoy DA. Intracellular growth of bacteria. Methods Enzymol (1994) 236:463-7. doi:10.1016/0076-6879(94)36034-0

45. Kuhn M, Prevost MC, Mounier J, Sansonetti PJ. A nonvirulent mutant of Listeria monocytogenes does not move intracellularly but still induces polymerization of actin. Infect Immun (1990) 58(11):3477-86.

46. Becavin C, Bouchier C, Lechat P, Archambaud C, Creno S, Gouin E, et al. Comparison of widely used Listeria monocytogenes strains EGD, 10403S, and EGD-e highlights genomic variations underlying differences in pathogenicity. MBio (2014) 5(2):e969-914. doi:10.1128/mBio.00969-14

Conflict of Interest Statement: The authors declare that the research was conducted in the absence of any commercial or financial relationships that could be construed as a potential conflict of interest.

Copyright (c) 2017 Cheng, Jiang, Ma, Wang, Han, Sun, Yang, Chen, Yu, Hang, Liu, Wang, Fang, Huang, Fang, Cai, Freitag and Song. This is an open-access article distributed under the terms of the Creative Commons Attribution License (CC BY). The use, distribution or reproduction in other forums is permitted, provided the original author(s) or licensor are credited and that the original publication in this journal is cited, in accordance with accepted academic practice. No use, distribution or reproduction is permitted which does not comply with these terms. 